\title{
Um estudo da mudança das ações docentes de um supervisor do PIBID-Matemática
}

\author{
A study of the change teacher action of a PIBID-Mathematics supervisor
}

\author{
Diego Fogaça Carvalho ${ }^{1}$ \\ Sergio de Mello Arruda ${ }^{2}$ \\ Marinez Meneghello Passos ${ }^{3}$
}

\begin{abstract}
Resumo
Neste artigo analisamos a ação docente de um supervisor do PIBID-Matemática, por meio de um instrumento de análise denominado Matriz 3x3. O instrumento permite categorizar as relações estabelecidas pelos professores com o saber, o ensinar e o aprender para qualquer conteúdo escolar. Os dados foram obtidos pela observação das aulas do supervisor para três turmas do sexto ano do ensino fundamental. Com base em comparações realizadas sobre a ação desse professor, antes e após uma intervenção feita pelo pesquisador no campo, observamos que essas ações mudaram: antes, suas aulas focavam mais o ensino, demonstrando maior interesse com sua conduta e a maneira como a exposição do conteúdo e manutenção da ordem eram realizadas; após a intervenção, elas passaram a focar mais a aprendizagem, possibilitando que os alunos fossem mais ativos durante esse processo, considerando suas percepções e soluções apresentadas sobre o conteúdo abordado.
\end{abstract}

Palavras-chave: PIBID-Matemática; Relação com o saber; Matriz 3x3; Formação em serviço.

\begin{abstract}
In this article we analyze the action of a mathematics teacher, supervisor of a PIBID-Mathematics, through an analytical tool called Matrix 3x3. The instrument allows the categorization the relationships established by teachers with the knowledge, the teaching and the learning of any school content. The data were obtained by observing the supervisor's classes for three classrooms of the sixth year of elementary school. Based on comparisons made on the action of this teacher, before and after an intervention made by the researcher in the field, we observed that the actions of the supervisor changed: before, his classes focused more on teaching, showing more interest in his behavior and the way the content and command maintenance were performed; after the intervention they began to focus more on student learning, allowing students to be more active during this process, considering their perceptions and solutions introduced on the content approached.
\end{abstract}

Keywords: PIBID-Mathematics; Relationship with knowledge; Matrix 3x3; In-service formation.

Submetido em: 24/05/2017 - Aceito em: 03/04/2018 - Publicado em: 13/06/2018

${ }^{1}$ Pós-doutorando em Ensino de Ciências e Educação Matemática pela Universidade Estadual de Londrina UEL. Com apoio da CNPq. E-mail: diegofocarva@gmail.com.

${ }^{2}$ Doutor em Educação pela Universidade de São Paulo - USP - SP. Professor Sênior da Universidade Estadual de Londrina - UEL. Com apoio do CNPq. E-mail: sergioarruda@ sercomtel.com.br.

${ }^{3}$ Doutora em Educação para a Ciência pela Universidade Estadual Paulista "Júlio de Mesquita Filho" - Unesp Bauru. Professora Sênior da Universidade Estadual de Londrina - UEL. Com apoio da Fundação Araucária. E-mail: marinezmp@sercomtel.com.br. 


\section{Introdução}

Há cerca de dez anos a Coordenação de Pessoal de Nível Superior (CAPES) tem financiado diversos programas que tomaram a valorização da docência como objetivo central. O Programa Institucional de Bolsa de Iniciação à Docência (PIBID) tem sido uma dessas políticas que focam principalmente na formação inicial de professores por meio da concessão de bolsas para que "alunos de licenciatura exerçam atividades pedagógicas em escolas públicas de educação básica" (CAPES, 2013, p.67). Dos subprojetos, em geral separados pelas áreas disciplinares, fazem parte estudantes das licenciaturas, professores das universidades (coordenadores de área) e professores das escolas participantes (supervisores). Podemos afirmar que um dos diferenciais do PIBID é que ele considera que os professores das escolas possuem saberes específicos que são mobilizados, utilizados e produzidos por eles no âmbito de suas tarefas cotidianas (Tardif, 2002, p.228), devendo, por isso, atuar como coformadores e não apenas como receptores de estudantes da universidade.

De um modo geral, compreendemos o PIBID como uma configuração particular de aprendizagem docente que visa proporcionar aos professores em formação, principalmente inicial, mas também em serviço, experiências sobre as relações com o saber, com o ensinar e com o aprender que ocorrem em uma sala de aula.

Em nosso grupo de pesquisa, realizamos várias investigações que tomaram o PIBID como objeto de estudo, entre elas as desenvolvidas por Maistro (2012) e Largo (2013). Em geral, as considerações elaboradas apontam que o PIBID de fato tem proporcionado experiências formativas muito interessantes aos estudantes das licenciaturas. No sentido de justificar em qual sentido o presente artigo traz novidades para as pesquisas nessa área, comentamos a seguir os resultados de um levantamento realizado em alguns periódicos.

Inicialmente realizamos um levantamento na $\mathrm{Scielo}^{4}$ utilizando a palavra pibid como termo de busca ${ }^{5}$. A pesquisa retornou 22 artigos. Na maior parte deles (15), os dados diziam respeito às percepções, ações e/ou produções dos bolsistas de iniciação (licenciandos); outros artigos (3) tomaram como foco de análise um determinado projeto; em menor quantidade encontramos artigos (2) que mesclaram reflexões sobre temas gerais de interesse voltado a contextos específicos; finalmente, na Scielo, foram encontrados também artigos (2) em que os autores realizaram análises mais gerais, envolvendo o PIBID.

Especificamente em relação à Educação Matemática, encontramos 9 artigos publicados entre 2010 e 2016 que tomaram o PIBID como campo da investigação. O levantamento foi realizado em algumas das revistas representativas da área. Seguimos o

\footnotetext{
4 A opção por realizar o levantamento somente na plataforma Scielo se deu pela concentração de periódicos brasileiros, bem como pela forma com que a busca de artigos foi estruturada, facilitando a identificação e organização por índice de assuntos e índice de autor. Por outro lado, a indexação dos periódicos se dá por meio de critérios que levam em consideração a relevância das pesquisas publicadas, bem como sua periodicidade.

${ }^{5}$ Levantamento e interpretação realizados no período de 20 abr. 2017 a 27 abr. 2017.
} 
mesmo procedimento de busca utilizado na Scielo. Foram selecionadas publicações da Educação Matemática em Revista (Alves et al., 2010; Figueroa et al., 2011; Bovo et al., 2012; Alves et al., 2012), da Zetetiké (Bampi et al., 2013), do Bolema (Pranke; Frison, 2015), da revista Perspectivas da Educação Matemática (Xavier; Silva, 2015; Rodrigues et al., 2016) e da Revista Eletrônica de Educação Matemática (Marchetto, 2016). Em apenas um desses artigos (Rodrigues et al., 2016), o supervisor foi considerado como sujeito da pesquisa, respondendo a questionários.

Em resumo, nenhuma das pesquisas cujos resultados foram publicados nesses periódicos preocupou-se em estudar o PIBID como espaço para a formação em serviço. $\mathrm{O}$ presente artigo procura preencher essa lacuna, ao apresentar os resultados de uma intervenção que demonstra as potencialidades do PIBID em provocar mudanças na prática docente dos professores participantes que atuam como supervisores ${ }^{6}$ nas escolas. De um modo geral podemos afirmar que a intervenção realizada pelo pesquisador adotou um dos pressupostos fundamentais do paradigma do professor reflexivo, qual seja: a defesa da pesquisa como um "instrumento de formação de professores" (Pimenta; Lima, 2011, p.22).

Este artigo tem dois objetivos: primeiro, analisar em detalhes a ação docente de um professor de Matemática, supervisor do PIBID, mostrando a distribuição de suas ações (subcategorias emergentes) pelas categorias a priori do principal instrumento de análise adotado - a Matriz 3x3; posteriormente, analisamos a mudança na ação docente do professor, por efeito de uma intervenção realizada pelo pesquisador.

$\mathrm{Na}$ sequência, apresentamos os fundamentos teóricos do instrumento de análise denominado Matriz 3x3.

\section{A Matriz 3x3 como um instrumento de análise da ação docente}

Em nosso grupo de pesquisa, o problema de compreender e interpretar a ação docente, considerada como a ação que o professor desenvolve em sala de aula, tendo em vista o ensinar e o aprender, tornou-se foco de investigações a partir do ano de 2010, principalmente depois da publicação do artigo Um novo instrumento para a análise da ação do professor em sala de aula (Arruda; Lima; Passos, 2011).

Tais pesquisas se fundamentam nas relações com o saber, conforme estabelecidas por Charlot, mas enfatizam, em especial, suas aplicações na sala de aula. Nesse sentido, dois pressupostos passaram a balizar nossas pesquisas nos últimos anos: (i) a ação do professor pode ser compreendida em função das relações que ele estabelece com o saber, com o ensinar e com o aprender em sala de aula; (ii) uma sala de aula padrão, ou seja, um sistema constituído por um professor $\mathrm{P}$ que desenvolve um conteúdo $\mathrm{S}$ com uma turma de estudantes E, pode ser representada pela Figura 1:

\footnotetext{
${ }^{6}$ De acordo com CAPES (2013, p.72), os supervisores são os “ professores das escolas públicas, onde acontece a prática docente, designados para acompanhar os bolsistas de iniciação à docência".
} 


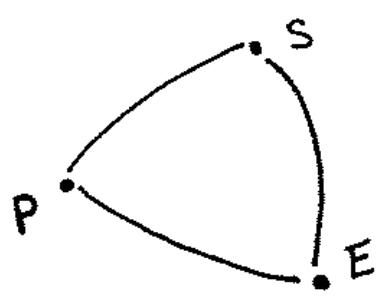

Figura 1 - Sistema didático

Fonte: Chevallard (2005, p.26)

Entendemos a Figura 1, denominada por Chevallard de sistema didático, como um complexo sistema de relações com o saber, em que as arestas PS, PE e ES são interpretadas da seguinte forma: P-S representa a relação do professor com o conteúdo da disciplina (ou, de modo mais geral, como o saber docente); P-E é a relação do professor com os estudantes e representa o ensino; E-S é a relação dos estudantes com o saber e representa a aprendizagem (Arruda; Lima; Passos, 2011).

Em função desses pressupostos, a ação docente, objeto de estudo cujos resultados trazemos neste artigo, foi assumida como a ação desenvolvida pelo professor no interior do triângulo representado pela Figura 1.

Considerando que a relação com o saber "é uma forma mais geral da relação com o mundo" (Charlot, 2000, p.77) e que, no nosso caso, o mundo é o mundo escolar, então para esse mundo podemos definir os seguintes tipos de relações que um professor poderia estabelecer na escola, ou, mais especificamente, dentro da sala de aula (Arruda; Lima; Passos, 2011, p.145):

1) A relação epistêmica com o saber diz respeito à relação com o saber enquanto um objeto do mundo a ser apropriado e compreendido; um saber dotado de objetividade, consistência e estrutura independentes; um saber "existente em si mesmo", "depositado em objetos, locais e pessoas" e imerso em um "universo de saberes distinto do mundo da ação, das percepções e das emoções" (Charlot, 2000, p.69) ${ }^{8}$.

2) A relação pessoal com o saber diz respeito à "relação de identidade com o saber"; o saber enquanto objeto que faz sentido, que é parte da história pessoal do sujeito, de sua vida e de suas expectativas (Charlot, 2000, p.72); é o saber enquanto objeto de desejo, de interesse; o saber que o sujeito "gosta" e que o faz mobilizar-se à sua procura.

\footnotetext{
${ }^{7}$ Para Charlot, a relação com o saber é, de uma forma mais geral, a relação com o aprender (Charlot, 2000, p.86).

${ }^{8}$ Charlot distingue o "saber-objeto", isto é, o saber objetivado e o "objeto-saber", que seria o suporte material do saber-objeto, por exemplo, um livro (Charlot, 2000, p.75, nota 10).
} 
3) A relação social com o saber diz respeito ao fato que o sujeito nasce inscrito em um espaço social, ocupando uma posição social objetiva ${ }^{9}$, que the definem o contexto inicial em que ele vai se relacionar com o saber; nesse meio o saber possui valores dados pela comunidade em que o sujeito vive, recebendo o impacto das expectativas e aspirações de outros com relação a ele (Charlot, 2000, p.73).

Aplicando as relações epistêmicas, pessoais e sociais ao modelo da sala de aula (Figura 1), obtemos a denominada Matriz 3x3, apresentada no Quadro 1.

Quadro 1 - Matriz 3x3

\begin{tabular}{|c|c|c|c|}
\hline $\begin{array}{l}\text { Relações do } \\
\text { professor }\end{array}$ & $\begin{array}{c}1 \\
\text { com o conteúdo } \\
(\text { segmento } \mathrm{P}-\mathrm{S})\end{array}$ & $\begin{array}{c}2 \\
\text { com o ensino } \\
(\text { segmento } \mathrm{P}-\mathrm{E})\end{array}$ & $\begin{array}{c}3 \\
\text { com a aprendizagem } \\
(\text { segmento E-S })\end{array}$ \\
\hline $\begin{array}{c}\mathbf{A} \\
\text { Epistêmica }\end{array}$ & $\begin{array}{c}\text { Setor 1A } \\
\text { Diz respeito à relação } \\
\text { epistêmica do professor com } \\
\text { o conteúdo; à busca por } \\
\text { compreendê-lo cada vez } \\
\text { mais; à relação com os } \\
\text { objetos, pessoas e locais que } \\
\text { possam contribuir para } \\
\text { melhorar sua compreensão } \\
\text { do conteúdo, como livros, } \\
\text { revistas, vídeos, internet, } \\
\text { biblioteca, universidades etc. }\end{array}$ & $\begin{array}{c}\underline{\text { Setor 2A }} \\
\text { Diz respeito à relação } \\
\text { epistêmica do professor com } \\
\text { o ensino; à busca por } \\
\text { compreendê-lo cada vez } \\
\text { mais; à relação com os } \\
\text { objetos, pessoas e locais que } \\
\text { possam contribuir para } \\
\text { melhorar sua compreensão } \\
\text { do ensino, como livros, } \\
\text { revistas, vídeos, internet, } \\
\text { biblioteca, universidades etc. }\end{array}$ & $\begin{array}{c}\underline{\text { Setor 3A }} \\
\text { Diz respeito à relação } \\
\text { epistêmica do professor com } \\
\text { a aprendizagem de seus } \\
\underline{\text { alunos; à busca por }} \\
\text { compreendê-la cada vez } \\
\text { mais; à relação com os } \\
\text { objetos, pessoas e locais que } \\
\text { possam contribuir para } \\
\text { melhorar sua compreensão } \\
\text { da aprendizagem, como } \\
\text { livros, revistas, vídeos, } \\
\text { internet, biblioteca, } \\
\text { universidades etc. }\end{array}$ \\
\hline $\begin{array}{c}\text { B } \\
\text { Pessoal }\end{array}$ & $\begin{array}{c}\text { Setor 1B } \\
\text { Diz respeito à relação } \\
\text { pessoal do professor com o } \\
\text { conteúdo; ao sentido que o } \\
\text { conteúdo adquire para ele e } \\
\text { o quanto determina sua } \\
\text { identidade profissional; } \\
\text { quanto o professor gosta e se } \\
\text { envolve com a matéria que } \\
\text { ensina; como ele avalia sua } \\
\text { própria compreensão dessa } \\
\text { matéria. }\end{array}$ & $\begin{array}{c}\text { Setor 2B } \\
\text { Diz respeito à relação } \\
\text { pessoal do professor com o } \\
\text { ensino; ao sentido que o } \\
\text { ensino adquire para ele e o } \\
\text { quanto determina sua } \\
\text { identidade profissional; } \\
\text { quanto o professor gosta e se } \\
\text { envolve com o ato de } \\
\text { ensinar; como ele avalia sua } \\
\text { própria atividade pedagógica } \\
\text { etc. }\end{array}$ & $\begin{array}{c}\text { Setor 3B } \\
\text { Diz respeito à relação } \\
\text { pessoal do professor com a } \\
\underline{\text { aprendizagem de seus }} \\
\underline{\text { alunos; ao sentido que a }} \\
\text { aprendizagem adquire para } \\
\text { ele e o quanto determina sua } \\
\text { identidade profissional; } \\
\text { quanto o professor gosta e se } \\
\text { envolve com a } \\
\text { aprendizagem de seus } \\
\text { alunos; como ele avalia a } \\
\text { aprendizagem de seus alunos } \\
\text { etc. }\end{array}$ \\
\hline $\begin{array}{c}\mathrm{C} \\
\text { Social }\end{array}$ & $\begin{array}{c}\text { Setor 1C } \\
\text { Diz respeito aos valores do } \\
\text { professor em relação ao } \\
\text { conteúdo que ensina; a } \\
\text { quanto o professor partilha } \\
\text { de uma comunidade de } \\
\text { educadores e de suas trocas }\end{array}$ & $\begin{array}{c}\text { Setor } 2 \mathrm{C} \\
\begin{array}{c}\text { Diz respeito aos valores do } \\
\text { professor em relação ao }\end{array} \\
\text { ensino que pratica; a quanto } \\
\text { o professor partilha de uma } \\
\text { comunidade de educadores e } \\
\text { de suas trocas e práticas no }\end{array}$ & $\begin{array}{c}\text { Setor 3C } \\
\text { Diz respeito aos valores do } \\
\text { professor em relação à } \\
\text { aprendizagem de seus } \\
\text { alunos; a quanto o professor } \\
\text { partilha de uma comunidade } \\
\text { de educadores e de suas }\end{array}$ \\
\hline
\end{tabular}

\footnotetext{
${ }^{9}$ Charlot distingue entre a posição social objetiva (a posição que ele ocupa em um espaço social, por ter nascido e crescido em uma determinada família, por exemplo) e a posição social subjetiva (que é a interpretação subjetiva que o sujeito faz de sua posição social objetiva, o que ele fará com isso) (Charlot, 2000, p.22).
} 


\begin{tabular}{|l|c|c|c|}
\hline & $\begin{array}{c}\text { e práticas no que diz respeito } \\
\text { ao conteúdo; às negociações } \\
\text { do professor com as } \\
\text { instâncias administrativas no } \\
\text { que diz respeito ao conteúdo } \\
\text { que ensina etc. }\end{array}$ & $\begin{array}{c}\text { que diz respeito ao ensino; } \\
\text { às negociações do professor } \\
\text { com as instâncias } \\
\text { administrativas no que diz } \\
\text { respeito ao ensino que } \\
\text { pratica etc. }\end{array}$ & $\begin{array}{c}\text { trocas e práticas no que diz } \\
\text { respeito à aprendizagem; às } \\
\text { negociações do professor } \\
\text { com as instâncias } \\
\text { administrativas no que diz } \\
\text { respeito à aprendizagem dos } \\
\text { alunos etc. }\end{array}$ \\
\hline
\end{tabular}

Fonte: Adaptado de Arruda e Passos (2015, p.9-10).

Como podemos observar, a representação na forma de Matriz que trazemos na Tabela 1 é formada por três colunas, que são as arestas do triângulo didático-pedagógico (Figura 1), em que P-S diz respeito às relações do professor com o conteúdo; P-E refere-se às relações do professor com o ensino que pratica; e E-S diz respeito às relações do professor com a aprendizagem de seus alunos.

Tal Matriz 3x3 constitui-se de um instrumento que possui nove células, cada uma representando uma categoria a priori. Essas categorias permite-nos observar a ação docente diretamente (por meio da ação efetiva que o professor desenvolve em sala de aula) ou pelos diálogos que ele estabelece com seus alunos. No caso desta pesquisa, a ação está sendo inferida por meio dos diálogos.

Tendo apresentado a Matriz 3x3, a seguir discorremos sobre os procedimentos metodológicos adotados na investigação, bem como trazemos alguns detalhes a respeito do contexto pesquisado.

\section{As coletas de dados e o contexto investigado}

Com a intenção de estudar a ação docente do sujeito desta pesquisa (supervisor), foi necessário em alguns momentos estabelecer relações entre os próprios setores (células) da Matriz, ampliando o que os autores de origem (Arruda; Lima; Passos, 2011) estabeleciam como critérios de alocação. Esses ajustes e desdobramentos foram possibilitados pela adoção dos procedimentos da Análise Textual Discursiva, que nos permitiram estabelecer convergências entre as unidades de análise, partindo de categorias a priori e chegando a subcategorias emergentes. Uma fragmentação do $\operatorname{corpus}^{10}$ (unitarização), seguida de reestruturação (categorização e subcategorização), é proveniente das interpretações dos pesquisadores que almejavam ir além de uma leitura convencional (Moraes; Galiazzi, 2011).

Podemos separar a coleta de dados em três momentos:

i) Primeiro momento: observação pré-intervenção. Observação sobre a maneira como o supervisor planejava e realizava as aulas e estabelecia as atribuições para cada um dos licenciandos (bolsistas do PIBID). Duração de seis meses.

ii) Segundo momento: intervenção. Um pesquisador (um dos autores) interveio no campo de pesquisa, procurando instituir um ambiente colaborativo de modo que as

\footnotetext{
${ }^{10}$ De acordo com Bardin (2016, p.126) "O corpus é o conjunto os documentos tidos em conta para serem submetidos aos procedimentos analíticos".
} 
atividades relativas à docência, entre elas, o planejamento e a condução das aulas, fossem compartilhadas entre o supervisor e os estudantes. Além disso, foram promovidos momentos de reflexão, em que pesquisador e supervisor conversavam a respeito das aulas ministradas pelos bolsistas do PIBID, visando conscientizar o supervisor sobre seu papel de (co)formador de professores. Duração de cinco semanas.

iii) Terceiro momento: observação pós-intervenção. Observação de treze aulas de Matemática, conduzidas exclusivamente pelo supervisor, quando da ausência dos bolsistas do PIBID. As aulas observadas ocorreram nas mesmas semanas do momento ii.

Todas as tomadas de dados foram realizadas em sextos anos do Ensino Fundamental de uma escola da rede pública paranaense.

$\mathrm{Na}$ continuidade, apresentamos os dados e as análises, que contribuíram com a caracterização e elaboração da distribuição das ações didático-pedagógicas realizadas pelo supervisor durante suas aulas. Os dados foram expostos na seguinte ordem: primeiro as ações e subcategorias de ações do supervisor no terceiro momento, ou seja, após a intervenção; em seguida, analisamos as mudanças na ação do supervisor, comparando suas aulas antes e após a intervenção.

\section{A ação docente do supervisor no terceiro momento}

Nesta primeira parte da apresentação e análise dos dados, focamos apenas nas aulas do supervisor no momento pós-intervenção.

Os diálogos estabelecidos nas treze aulas foram fragmentados em 1.095 unidades de análise. Durante esse processo, considerou-se como critério a reação dos alunos às ações realizadas pelo supervisor, ou seja, classificamos cada um dos fragmentos de acordo com a forma com que os alunos reagiram às falas do supervisor. Acomodamos cada unidade nas células da Matriz 3x3 e, posteriormente, em um novo processo interpretativo, procuramos construir subcategorias com o objetivo de elucidar e aprofundar o estudo dessas ações.

A seguir, tecemos alguns comentários, coluna a coluna, sobre essa distribuição (que pode ser observada no Quadro 8) e apresentamos as subcategorias que emergiram da acomodação dos relatos em cada uma das células. Posteriormente, realizamos nossas considerações a respeito do que foi possível evidenciar mediante essa organização.

Células sem incidência de registros.

Como veremos adiante, não ocorreram registros de unidades de análise nas células da primeira coluna e nem nas células $2 \mathrm{~B}$ e $3 \mathrm{~B}$. Ou seja, não houve, por parte do supervisor, menção explícita às suas relações com o conteúdo e nem às suas relações pessoais com o ensino e com a aprendizagem. O supervisor manifestou-se em suas aulas sempre nas dimensões epistêmicas e sociais. 
DOI: https://doi.org/10.20396/zet.v26i2.8649577

\section{Distribuição das unidades de análise na segunda coluna.}

Célula 2A (referente ao ensino em sua dimensão epistêmica).

Nessa célula, foram alocadas 335 unidades de análise (ver Quadro 8), o equivalente a um pouco mais de trinta por cento $(30,6 \%)$ do total de excertos. Provenientes de um processo dedutivo emergiram nove subcategorias indicadas no Quadro 2 (na terceira coluna, consta a quantidade de vezes que a unidade de análise ocorreu na subcategoria):

Quadro 2 - Subcategorias da célula 2A

\begin{tabular}{|c|r|c|}
\hline N. & Subcategoria & Quantidade \\
\hline 1 & $\begin{array}{c}\text { Expõe oralmente: procedimentos de resolução de exercícios, propriedades de } \\
\text { conteúdo matemático, enunciados das tarefas }\end{array}$ & 240 \\
\hline 2 & Comenta os registros da lousa & 58 \\
\hline 3 & Realiza perguntas de complementação & 15 \\
\hline 4 & Ignora a solução ou as perguntas apresentadas pelo aluno & 8 \\
\hline 5 & Defende o ensino que realiza & 5 \\
\hline 6 & Complementa/corrige a solução apresentada pelo aluno & 3 \\
\hline 7 & Retoma o processo de ensino & 2 \\
\hline 8 & Determina a data da prova & 1 \\
\hline 9 &
\end{tabular}

Fonte: os autores

Com relação à célula 2A, por 240 vezes o supervisor Expõe, oralmente, procedimentos de resolução de exercícios, propriedades de conteúdo matemático, enunciados das tarefas, ocupando a posição de protagonista de todo o diálogo realizado; explicitando e articulando, por meio de revisões, os conteúdos matemáticos já estudados; construindo relações com o novo conteúdo; lendo os enunciados das questões, visando iniciar a correção ou explicar aos alunos a forma de resolvê-las; expondo propriedades dos conceitos matemáticos não identificados pelos alunos.

A seguir trazemos dois exemplos de períodos transcritos e que foram acomodados nessa subcategoria.

Então é como você falou, divisão em partes. Falar em uma divisão significa partir. Quando você fala divisão em partes, significa que as partes da sua fração serão também iguais. (Supervisor, $1^{\mathrm{a}}$ semana da intervenção, $6^{\circ} \mathrm{A}$ )

Vocês lembram quando nós fizemos... quando eu ensinei a vocês a fazerem a divisão? Vocês lembram que lá na divisão aparecia esse símbolo aqui, ou se não esse símbolo aqui. E eu falei para vocês que quando a gente vai representar uma operação de divisão. Nós podemos fazer o quê? Utilizar quatro formas diferentes. As quatro formas diferentes..., e ainda tem as chaves que eu ainda não falei. Mas se a gente foi usar essas daqui. Eu posso usar essa simbologia, eu posso usar essa, posso usar a barrinha deitada... quer dizer, a barrinha inclinada ou a barrinha deitada. (Supervisor, $5^{\mathrm{a}}$ semana da intervenção, $6^{\circ} \mathrm{C}$ )

Os alunos ocuparam uma posição secundária, de ouvinte da informação, e suas manifestações se resumiram às pequenas frases que indicaram concordância ou pedidos de reiteração, visando compreender a fala do supervisor. 
Interpretamos que a prática de expor informações aos estudantes de forma clara, estando disposto a repeti-las quando necessário, pode ser uma das características do perfil desse supervisor, integrando a forma como realiza a gestão da matéria no processo de interação com os alunos. Para Gauthier et al. (2013, p.215), "os professores que dão instruções claras, explícitas, redundantes (repetidas mais de uma vez) e compreendidas por todos os alunos levam-nos a se aplicarem mais às tarefas durante o trabalho individual".

Na segunda subcategoria de 2A - Comenta os registros da lousa - composta por 58 recorrências, acomodamos os comentários em que o supervisor fez uso de outras linguagens e representações do conteúdo matemático, associadas à exposição oral, para ensinar. Essas recorrências referem-se à sistematização das soluções, bem como as outras representações, como os desenhos, que tiveram o objetivo de complementar o conteúdo exposto oralmente.

Uma das práticas associada ao ensino tradicional e identificada nas subcategorias 15 vezes - Realiza perguntas de complementação - trata de questionamentos designados por "perguntas de complementaridade, isto é, o professor começa uma frase e deixa para os alunos terminarem. Por exemplo: 'Este é um movimento retilíneo e...?'” (Carvalho, 2012, p.23). Essas perguntas trazem a ilusão de que os alunos estão pensando, principalmente pela participação. Todavia são, em sua maioria, perguntas conhecidas pelos alunos e de fácil resposta, além de serem caracterizadas pela brevidade do tempo entre pergunta e resposta.

Integrada à prática das perguntas de complementação, associamos duas subcategorias: Ignora a solução ou as perguntas apresentadas pelo aluno (8 incidências) e Complementa/corrige a solução apresentada pelo aluno (3 incidências). Na primeira, temos os momentos em que o supervisor não considerou as contribuições dos alunos no processo de correção das atividades, fato que impossibilitou a viabilização de um diálogo argumentativo, bem como a evidenciação dos conhecimentos que os alunos possuíam (Carvalho, 2012). Na segunda, ficou evidente que o professor não se preocupava com a compreensão do aluno, mas sim com o prosseguimento da aula.

Pouco a pouco se tornaram evidentes algumas mudanças na prática do supervisor em sala de aula, fato inclusive percebido pelos alunos, que o questionaram. Diante dessa interpelação, ele Defende o ensino que realiza por 5 vezes, justificando que está dando continuidade à forma com que trabalhavam em sala de aula seus supervisionados.

Contemplada 3 vezes - Sugere outras soluções para as tarefas propostas - essa subcategoria diz respeito aos momentos em que o supervisor procura realizar em sala de aula um inventário a respeito da diversidade de soluções apresentadas pelos alunos para as tarefas. Contudo, ele não obteve êxito com tal proposição, pois os alunos não corresponderam às suas expectativas, levando-o a propor outros encaminhamentos, entre eles a utilização de material manipulável para a validação dos resultados. Cabe informar que essa prática de realizar a correção a partir de uma série de respostas elaboradas pelos alunos foi prevista no início do planejamento da intervenção e era adotada pelos estudantes da licenciatura. 
Por fim, foram registradas as subcategorias: Retoma o processo de ensino (2 incidências); Determina a data da prova (1 incidência) - interpretadas por nós como ações estritamente relacionadas ao ensino.

Célula 2C (referente ao ensino em sua dimensão social).

Nela foram acomodadas 103 unidades de análise (como já indicamos, verificar no Quadro 8), que representam aproximadamente dez por cento dos registros $(9,4 \%)$, distribuídas em quatro subcategorias mostradas no Quadro 3:

Quadro 3 - Subcategorias da célula 2C

\begin{tabular}{|c|c|c|}
\hline N. & Subcategoria & Quantidade \\
\hline 1 & Organiza o ambiente para o ensino & 59 \\
\hline 2 & Faz a manutenção da ordem & 35 \\
\hline 3 & Finaliza a aula & 5 \\
\hline 4 & Registra a frequência dos alunos & 4 \\
\hline
\end{tabular}

Fonte: os autores

Com relação à célula $2 \mathrm{C}$, duas subcategorias merecem destaques: Organiza $o$ ambiente para o ensino, com 59 remissões, e Faz a manutenção da ordem, com 35 remissões. Ambas estão relacionadas aos momentos em que o supervisor interveio em interação direta com os alunos, visando configurar um ambiente propício para a prática do seu ensino.

$\mathrm{Na}$ primeira, foram acomodadas as manifestações em que o supervisor orientou a organização da sala para o desenvolvimento da aula. Essas ações foram tanto físicas quanto argumentativas: físicas, quando solicita aos alunos a acomodação das filas/carteiras em dupla; argumentativas, quando questiona se os alunos haviam corrigido os exercícios da aula anterior. A seguir inserimos um exemplo desses diálogos tão recorrentes.

Supervisor: Pessoal, na aula anterior nós tínhamos terminado de corrigir o exercício seis. Aluno: a gente tinha terminado de corrigir a do quatro e do cinco. (Diálogo registrado na $5^{\mathrm{a}}$ semana de intervenção, na turma $6^{\circ} \mathrm{B}$ )

$\mathrm{Na}$ segunda, temos as situações em que o professor chama a atenção dos alunos de diversas formas. Considerado por Gauthier et al. (2013) como um componente da Gestão de Classe, especificadamente em situação de interação com os alunos, o professor é levado a aplicar medidas disciplinares e sanções. Geralmente o professor emprega um sinal verbal e não obstrutor que consiste em uma simples repreensão como: Psiu! Espere! Pare com isso! Não!. Além do que foi exposto por Gauthier et al. (2013), acomodamos nessas subcategorias as repreensões realizadas pelo supervisor com o intuito de que os alunos permanecessem calados e atentos às orientações de como proceder com as tarefas, ou seja, o estabelecimento de uma ordem pedagógica, conforme podemos observar no seguinte exemplo:

Supervisor: Então, sem conversa à toa, você tem o seu companheiro aí do lado, não quero ninguém virado para trás só batendo papo. Inclusive essas carteiras estão muito grudadas e eu quero que vocês venham mais para frente. (Supervisor, $4^{\mathrm{a}}$ semana da intervenção) 
De acordo com Tardif (2002, p.221), “[...] a ordem na sala de aula é certamente condicionada pela organização física e social da escola e das salas de aula, mas é ao mesmo tempo uma ordem construída pela ação do professor em interação com os alunos". Em suma, a manutenção da ordem se caracterizou em $2 \mathrm{C}$ pelo processo interativo que lhe é inerente e pelo ambiente, de acordo com o contexto dos dados analisados, configurado para o ensino a ser realizado pelo supervisor.

A subcategoria Finaliza a aula (5 recorrências) diz respeito às situações em que, após soar o sinal da troca de aulas, o professor ainda dá orientações visando à organização da sala (carteiras), bem como a necessidade de guardar o material manipulável em suas caixas.

Por fim, a última subcategoria dessa célula 2C - Registra a frequência dos alunos -, com 4 aparições, representa o trabalho burocrático do professor, popularmente conhecido como a 'hora da chamada'. Foi assumida por nós como uma situação interativa do professor com os alunos, relacionada à busca de uma ordem pedagógica inerente ao ensino praticado por ele.

\section{Distribuição das unidades de análise na terceira coluna.}

Célula 3A (referente à aprendizagem em sua dimensão epistêmica).

Nela alocamos 648 unidades de análise que representam em torno de sessenta por cento $(59,2 \%)$ de todos os comentários analisados. Com base nesses registros, foram elaboradas nove subcategorias, mostradas no Quadro 4:

Quadro 4 - Subcategorias da célula 3A

\begin{tabular}{|c|c|c|}
\hline N. & Subcategoria & Quantidade \\
\hline 1 & $\begin{array}{r}\text { Procura conhecer as percepções/soluções apresentadas pelos alunos referentes à } \\
\text { tarefa e ao conteúdo matemático }\end{array}$ & 369 \\
\hline 2 & Procura compreender a solução/procedimento realizado pelo aluno & 207 \\
\hline 3 & Mobiliza outras soluções & 33 \\
\hline 4 & Responde à dúvida apresentada pelos alunos & 29 \\
\hline 5 & Convida o aluno a criticar a solução encontrada & 5 \\
\hline 6 & Cndica que não pretende responder diretamente à dúvida do aluno & 2 \\
\hline 7 & Verifica a existência de dúvida & 1 \\
\hline 8 & Reformula o questionamento com base na fala do aluno & 1 \\
\hline 9 &
\end{tabular}

Fonte: os autores

Iniciamos os comentários sobre a célula 3A pela subcategoria Procura conhecer as percepções/soluções apresentadas pelos alunos referentes à tarefa e ao conteúdo matemático (369 unidades), a qual está relacionada aos momentos em que o supervisor (por meio de perguntas em sua maioria) procurou conhecer a maneira como os estudantes compreenderam o conteúdo matemático.

Com relação à segunda subcategoria dessa célula - Procura compreender a solução/procedimento realizado pelo aluno - (207 unidades), indicamos que ela está relacionada à anterior, pois nela inserimos os comentários em que o supervisor procurou, por meio de um novo questionamento, compreender o raciocínio utilizado pelo aluno ao resolver 
a tarefa. Nos excertos apresentados na continuidade, podemos evidenciar a articulação realizada pelo supervisor entre as duas subcategorias. Primeiramente, ele procura conhecer as percepções/soluções apresentadas pelos alunos:

Supervisor: Qual foi a regra de vocês? Aluno: divide ou multiplica a fração por qualquer número natural diferente de zero. Eu coloquei diferente de zero. (Diálogo registrado na $5^{\text {a }}$ semana de intervenção, na turma $6^{\circ} \mathrm{C}$ )

E, na sequência, busca compreender a solução apresentada:

Supervisor: Multiplicar ou dividir? Aluna: É, qualquer um dá. (Diálogo registrado na $5^{\mathrm{a}}$ semana de intervenção, na turma $6^{\circ} \mathrm{C}$ )

A subcategoria Mobiliza outras soluções, com 33 recorrências, refere-se aos diálogos em que o supervisor questiona os alunos sobre a resolução das tarefas de forma diferente das apresentadas.

Supervisor: Alguém respondeu diferente? Aluno: Eu, coloquei que sim e que sempre vai ter múltiplo de três. (Diálogo registrado na $5^{\text {a }}$ semana de intervenção, na turma $\left.6^{\circ} \mathrm{C}\right)$

Nesses momentos, temos indícios de valorização das respostas apresentadas pelos alunos para o desenvolvimento das aulas, conduta acordada com os estudantes da licenciatura e reiterada pelo supervisor e pelo pesquisador quando realizavam a supervisão compartilhada.

Para Carvalho (2012), levar os alunos a argumentarem torna-se uma nova habilidade do professor que contribui diretamente com a aprendizagem, pois a exposição argumentativa possibilita aos alunos construírem explicações dos fenômenos estudados e elaborarem o desenvolvimento do pensamento operacional. Aliada a esse processo temos a subcategoria Convida o aluno a criticar a solução encontrada, com uma recorrência de 5 vezes. Nela foram acomodados os excertos em que o supervisor fomentou os alunos a criticarem as soluções encontradas para as tarefas, procurando inseri-los em um processo argumentativo. Todavia, como os alunos não estavam acostumados com essa prática, eles demonstraram certas dificuldades em lidar com tal situação, levando o professor a expor as propriedades do conteúdo matemático e as soluções de algumas tarefas, abandonando a proposta argumentativa.

As seguintes subcategorias, Responde à dúvida apresentada pelos alunos, que foi verificada 29 vezes, e Corrige a solução apresentada pelo aluno, verificada 2 vezes, dizem respeito a quando o supervisor intervém de forma expositiva, focando no processo de aprendizagem do aluno ou em alguma demanda apresentada por ele. O exemplo a seguir ilustra situações como essas.

Aluno: Professor, as três têm o mesmo sentido. Não é? Supervisor: Mais ou menos... Hum, essa é do mesmo sentido daquela ali. (Diálogo registrado na $5^{\mathrm{a}}$ semana de intervenção, na turma $6^{\circ} \mathrm{B}$ )

As três últimas subcategorias apresentaram pouca frequência entre os relatos transcritos. Elas referem-se às situações 'pontuais' que aconteceram durante as aulas analisadas, todas com uma única remissão: Indica que não pretende responder diretamente à 
dúvida do aluno -, pois tinha a intenção de problematizar a dúvida apresentada; Verifica a existência de dúvida - visando identificar a existência de dúvidas dos alunos diante do conteúdo abordado naquela aula; Reformula o questionamento com base na fala do aluno ao perceber que não foi compreendido pelos alunos, procura reformular suas colocações com base nas compreensões apresentadas pelos próprios alunos.

Célula 3C (referente à aprendizagem em sua dimensão social).

Nessa célula, foram inseridos excertos representando menos de um por cento $(0,8 \%)$ dos analisados, dos quais emergiram duas subcategorias mostradas no Quadro 5:

Quadro 5 - Subcategorias da célula 3C

\begin{tabular}{|c|c|c|}
\hline N. & Subcategoria & Quantidade \\
\hline 1 & Pedidos de participação dos alunos durante a aula & 5 \\
\hline 2 & Diálogos de preocupação com a aprendizagem dos alunos & 4 \\
\hline
\end{tabular}

Fonte: os autores

$\mathrm{Na}$ célula $3 \mathrm{C}$, que se refere à aprendizagem em sua dimensão social, emergiram duas subcategorias - Pedidos de participação dos alunos durante a aula (5 vezes); Diálogos de preocupação com a aprendizagem dos alunos (4 vezes). Na primeira, o supervisor procurou mobilizar e destacar a importância de os alunos apresentarem suas compreensões relativas às soluções das tarefas e o conteúdo matemático para o desenvolvimento das aulas. Com relação à segunda, ele demonstra estar preocupado com os alunos que não conseguiram se concentrar, atrapalhando a ordem pedagógica que ele almejou instituir em sala de aula.

\section{Evidências de mudanças na prática docente do supervisor}

Uma das funções da Matriz 3x3 é revelar como se distribuiu a ação docente durante as aulas. Em particular, estamos interessados em verificar se o professor se dedica mais ao seu próprio ensino ou à aprendizagem dos alunos. Uma mudança nessa variável indica uma mudança na ação docente. Nessa segunda parte da apresentação e análise dos dados, queremos focar na mudança percebida na ação do professor supervisor em sala de aula, comparando a distribuição de suas ações antes e depois da intervenção.

Antes da intervenção, a distribuição das ações do supervisor pela Matriz 3x3 ocorreu conforme indicado no Quadro 6:

Quadro 6 - Distribuição de 196 unidades de análise na Matriz 3x3 (antes da intervenção)

\begin{tabular}{|c|c|c|c|c|}
\cline { 2 - 5 } \multicolumn{1}{c|}{} & $\begin{array}{c}\mathbf{1} \\
\text { Conteúdo }\end{array}$ & $\begin{array}{c}\mathbf{2} \\
\text { Ensino }\end{array}$ & $\begin{array}{c}\mathbf{3} \\
\text { Aprendizagem }\end{array}$ & Total \\
\hline $\begin{array}{c}\text { A } \\
\text { Epistêmica }\end{array}$ & $\mathbf{0}$ & $\mathbf{1 1 1}$ & $\mathbf{2}$ & $\mathbf{1 1 3}$ \\
\hline $\begin{array}{c}\text { B } \\
\text { Pessoal }\end{array}$ & $\mathbf{0}$ & $\mathbf{5}$ & $\mathbf{1}$ & $\mathbf{6}$ \\
\hline $\begin{array}{c}\text { C } \\
\text { Social }\end{array}$ & $\mathbf{0}$ & $\mathbf{3 5}$ & $\mathbf{4 2}$ & $\mathbf{7 7}$ \\
\hline Total & $\begin{array}{c}\mathbf{0} \\
(0 \%)\end{array}$ & $(77 \%)$ & $\mathbf{4 5}$ & $(39 \%)$ \\
\hline
\end{tabular}


Fonte: adaptado de Carvalho (2016, p.58)

Como podemos observar, antes da intervenção, a dedicação do professor às tarefas da sala de aula obedeceram à seguinte proporção: 77\% (ensino) e 23\% (aprendizagem). Ou seja, o professor se mostrava mais interessado em suas aulas (suas próprias ações) do que nas ações dos alunos. De certa forma, esse é um padrão que tem se repetido em nossas pesquisas, principalmente quando os sujeitos são estudantes em formação inicial. Em grande parte delas, verificamos que estudantes da licenciatura em Física (Arruda; Lima; Passos, 2011), Biologia (Maistro, 2012) e Matemática (Largo, 2013), nos momentos de regência de classe durante o estágio supervisionado, tendem a se preocupar mais com o seu próprio ensino do que com a aprendizagem dos alunos.

Ainda nessa fase (antes da intervenção), as subcategorias de ação (e suas UA) encontradas estão mostradas no Quadro 7:

Quadro 7 - Subcategorias de ação (antes da intervenção)

\begin{tabular}{|c|c|}
\hline $\begin{array}{l}\text { 2A (111) } \\
1 \text { - Chamada (26); } \\
2 \text { - Exposição Oral do Conteúdo Matemático (66); } \\
3 \text { - Seleção de exercícios em sala e tarefas para casa } \\
(12) ; \\
4 \text { - Esclarecimentos do sistema de promoção do } \\
\text { colégio (5); } \\
5 \text { - Reflexão do seu trabalho por meio do rendimento } \\
\text { dos alunos nas provas (2). }\end{array}$ & $\begin{array}{c}\mathbf{3 A}(\mathbf{2}) \\
1-\text { Retomada de Conteúdos antes da prova (2). }\end{array}$ \\
\hline $\begin{array}{l}\text { 2B (5) } \\
1 \text { - Expõe a maneira como os alunos devem } \\
\text { apresentar os cálculos na prova }(05) \text {. }\end{array}$ & $\begin{array}{l}\text { 3B (1) } \\
1 \text { - Preocupa-se em não marcar prova no mesmo dia } \\
\text { de prova de outra disciplina }(1) .\end{array}$ \\
\hline $\begin{array}{l}\text { 2C (35) } \\
1 \text { - Pedidos para que os alunos permaneçam em } \\
\text { silêncio (12); } \\
2 \text { - Negociação de conduta para com alunos que } \\
\text { apresentam necessidades especiais (10); } \\
3 \text { - Debate sobre o bullying na escola (13). }\end{array}$ & $\begin{array}{l}\text { 3C (42) } \\
1 \text { - Correção participativa das tarefas e exercícios } \\
\text { em sala de aula (30); } \\
2 \text { - Advertência para os alunos que não realizaram a } \\
\text { tarefa de casa (5); } \\
3 \text { - Supervisor pede para que alunos estudem mais } \\
\text { para a prova (3); } \\
4 \text { - Correção participativa da prova escrita na lousa } \\
\text { (4). }\end{array}$ \\
\hline
\end{tabular}

Fonte: adaptado de Carvalho (2016, p.58)

Após a intervenção, a distribuição das ações do supervisor alterou-se, como mostrado no Quadro 8.

Quadro 8 - Distribuição de 1.095 unidades de análise na Matriz 3x3 (após a intervenção)

\begin{tabular}{|c|c|c|c|c|}
\cline { 2 - 5 } \multicolumn{1}{c|}{} & $\begin{array}{c}\mathbf{1} \\
\text { Conteúdo }\end{array}$ & $\begin{array}{c}\mathbf{2} \\
\text { Ensino }\end{array}$ & $\begin{array}{c}\mathbf{3} \\
\text { Aprendizagem }\end{array}$ & Total \\
\hline $\begin{array}{c}\text { A } \\
\text { Epistêmica }\end{array}$ & $\mathbf{0}$ & $\mathbf{3 3 5}$ & $\mathbf{6 4 8}$ & $\mathbf{9 8 3}$ \\
\hline $\begin{array}{c}\text { B } \\
\text { Pessoal }\end{array}$ & $\mathbf{0}$ & $\mathbf{0}$ & $\mathbf{0}$ & $\mathbf{0}$ \\
\hline $\begin{array}{c}\text { C } \\
\text { Social }\end{array}$ & $\mathbf{0}$ & $\mathbf{1 0 3}$ & $\mathbf{9}$ & $(0 \%)$ \\
\hline Total & & & $\mathbf{9}$ & $10 \%$ \\
\hline
\end{tabular}




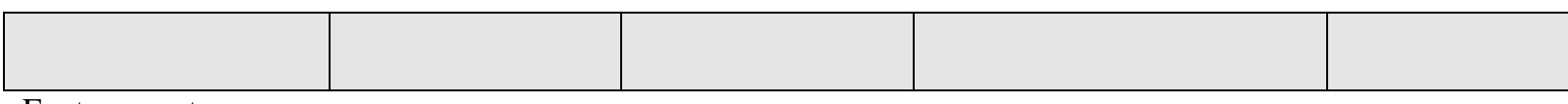

Fonte: os autores

Após a intervenção, a distribuição das ações mudou para 40\% (ensino) e $60 \%$ (aprendizagem). Ou seja, as aulas do supervisor eram mais 'tradicionais', isto é, focadas no ensino, antes da intervenção. Logo após, o supervisor passou a dedicar-se muito mais à aprendizagem de seus alunos, desenvolvendo ações em sala de aula que os envolvessem nas atividades $^{11}$.

Com relação às linhas, vemos que também houve mudanças. Antes da intervenção a proporção era de $58 \%$ (epistêmica) e $39 \%$ (social). Após a intervenção, mudou para $90 \%$ (epistêmica) e $10 \%$ (social). Isso indica que o professor diminuiu o tempo gasto com atividades com a turma toda e passou a se concentrar mais nos alunos, individualmente.

Interpretamos que a distribuição das subcategorias de ação na coluna da aprendizagem, exposta no Quadro 8, está diretamente relacionada com as discussões sobre o planejamento das aulas dos licenciandos, juntamente com o pesquisador em seu processo de intervenção. As aulas em questão visavam ser mais flexíveis para os alunos, promovendo a participação dos mesmos por meio da exposição dos raciocínios realizados na resolução das tarefas. Elas foram, também, inspiradas em leituras que tratavam das Investigações Matemáticas, tendência metodológica recentemente trabalhada com os licenciandos no curso superior.

Diante do que encontramos com a alocação, na coluna 3, dos fragmentos transcritos e a alta frequência das subcategorias na célula $3 \mathrm{~A}$, além da inter-relação entre elas, somos levados a inferir que o supervisor valeu-se das orientações realizadas durante os momentos de supervisão compartilhada, que tinham por objetivo a análise da prática do estudante da licenciatura. Ficou evidente que fez uso dessas práticas nos momentos em que conduziu, sozinho, as aulas de Matemática.

No sentido de fornecer maiores evidências sobre essa hipótese, trouxemos, como complemento aos dados, dois fragmentos de notas de campo do pesquisador:

FRAGMENTO 1. Após a realização das aulas, convidei o supervisor para conversar a respeito da condução realizada pelos bolsistas. Ele destacou que gostou da conduta de ambos os estudantes, destacou que um deles já estava pronto para ser professor, enquanto o outro necessitava ser mais ativo em sala de aula. Em resumo, para o supervisor, as aulas foram além de suas expectativas. Na sequência, apresentei meu posicionamento, ressaltando que os estudantes poderiam ter aproveitado mais as falas/percepções apresentadas pelos alunos durante o processo de exploração do material manipulável. O supervisor ficou pensativo e manteve-se um tempo em silêncio. Após, disse que compreendeu minha crítica e concorda que essa possibilidade poderia ter acontecido, mas ele teve a sensação de que os alunos tinham entendido. Comentei com o supervisor que eu não compartilhava dessa

\footnotetext{
${ }^{11}$ Vemos que, nos dois casos, as falas do supervisor que expressaram sua relação com o conteúdo foram nulas antes e após a intervenção. Em geral isso poderia ser explicado levando em conta que o conteúdo não era um problema para esse professor, pelo menos no momento em que as observações foram realizadas.
} 
DOI: https://doi.org/10.20396/zet.v26i2.8649577

compreensão, pois percebi que em muitos momentos os alunos falavam as soluções por falar, replicavam a fala dos colegas sem demonstrar compreensão. Diante desse cenário, a problematização da fala dos alunos, de suas compreensões, poderia ser uma forma de aprofundar as compreensões, levando o aluno a corrigir seus próprios equívocos. Nesse momento, percebi que o supervisor não estava à vontade, e tive a ideia de elaborar um e-mail de orientação aos bolsistas em dois momentos, um com o meu posicionamento e outro com o do supervisor, e assim foi feito (21 out. 2013).

FRAGMENTO 2. Inicialmente não tinha por objetivo acompanhar a prática do supervisor, o foco estava sobre a formação dos estudantes da licenciatura. Todavia, quando o supervisor conduziu pela primeira vez uma aula sem os bolsistas, percebi que algo estava diferente das centenas de aulas que anteriormente tinha acompanhado. Logo liguei a câmera e comecei a também considerar suas aulas como dados de pesquisa. Notei que o supervisor estava tentando conduzir as aulas na forma como os estudantes da licenciatura planejaram (sob minha orientação). Essa verificação aconteceu no dia 24 , dois dias após a condução da aula por duas estudantes e por termos compartilhado um momento de supervisão no qual destaquei a necessidade da bolsista valorizar as respostas e percepções apresentadas pelos alunos, utilizando-as como base para as problematizações (24 out. 2013).

Está claro, portanto, que a mudança observada na prática de sala de aula do supervisor ocorreu como efeito das participações do pesquisador no planejamento das aulas dos bolsistas do Programa PIBID e em diálogos ocorridos entre o supervisor e os bolsistas.

\section{Conclusões e Considerações Finais}

Neste artigo analisamos a ação docente de um supervisor do PIBID-Matemática, caracterizando-a por meio das relações estabelecidas com o saber, o ensinar e o aprender, evidenciadas pela Matriz 3x3.

$\mathrm{Na}$ primeira parte da análise, em que tratamos das aulas realizadas pelo supervisor após a intervenção, as suas ações foram descritas detalhadamente, tendo sido distribuídas principalmente pelas células 3A (relação epistêmica com a aprendizagem), 2A (relação epistêmica com o ensino) e 2C (relação social com o ensino). Enquanto subcategorias, as três principais ações realizadas pelo professor foram as seguintes:

a) Procura conhecer as percepções/soluções apresentadas pelos alunos referentes à tarefa e ao conteúdo matemático (369 UA - célula 3A).

b) Expõe oralmente procedimentos de resolução de exercícios, propriedades de conteúdo matemático, enunciados das tarefas (240 UA - célula 2A).

c) Procura compreender a solução/procedimento realizado pelo aluno (207 UA célula 3A).

Na segunda parte da análise, procuramos mostrar que as ações do supervisor mudaram depois da intervenção do pesquisador. Vimos que a prática anterior do supervisor, que se distribuiu principalmente na coluna do ensino na Matriz $3 \times 3$ no primeiro momento de coleta dos dados, teve seu foco deslocado para a coluna da aprendizagem, após a intervenção. Tal fato ficou evidente em função da quantidade de unidades de pesquisa alocadas na coluna 3. 
As três subcategorias principais de ação antes da intervenção foram as seguintes:

a) Exposição Oral do Conteúdo Matemático (66 UA - célula 2A).

b) Correção participativa das tarefas e exercícios em sala de aula (30 UA - célula $3 \mathrm{C})$.

c) Chamada (26 UA - célula 2A).

Como podemos ver, também as subcategorias de ação do supervisor mostraram uma mudança no tipo de ação realizada, pois ele procurou, após a intervenção, ouvir mais os alunos. Em seus diálogos e por meio de questionamentos, o supervisor deu mais ênfase ao processo de compreensão do conteúdo em estudo por parte dos alunos, proporcionando que eles se manifestassem com relação a esse processo de aprendizagem, socializando seus pensamentos com os colegas de classe.

Houve momentos em que o supervisor apresentou algumas fragilidades a respeito de como proceder diante de situações por ele identificadas em sala de aula. Inicialmente, as perguntas utilizadas por ele mostravam-se vagas, sem um objetivo pedagógico explícito. Entretanto, essa vulnerabilidade pode ser justificada quando se manifesta em um sujeito que se encontra em um processo formativo, no qual procura aprender a conduzir práticas pedagógicas diferentes daquelas a que está acostumado.

Diante disso, podemos afirmar que o ambiente de intervenção planejado pelo pesquisador (para trabalhar em colaboração com o supervisor) consistiu em uma configuração de aprendizagem da docência no contexto da formação contínua que favoreceu a aprendizagem docente e as mudanças nas práticas de sala de aula. Não temos elementos (e nem foi nosso objetivo na época da tomada de dados) para identificar as razões subjetivas que levaram o supervisor a mudar sua relação com o ensino e a aprendizagem. No entanto, cremos que esclarecimentos sobre esses fatos poderão contribuir para a pesquisa na formação contínua do professor de Matemática, principalmente na maneira como estruturar o ambiente de aprendizagem docente e as intervenções a serem planejadas em projetos como o PIBID.

\section{Referências}

Alves, M. R., Barbosa, M. S., Maia, F. A., Almeida, M. T. C., França, S. D., \& Franco, J. F. (2010). O Ensino integrado da matemática: um estudo em escola participante do PIBIDUNIMONTES. Educação Matemática em Revista, 15(31), 14-23.

Alves, M. R., Souza, G. V., Gomes, G. P., Maia, F. A., Almeida, M. T. C., \& França, S. D. (2012). Atividade envolvendo quadriláteros: um relato de experiência. Educação Matemática em Revista, 17(37), 24-31.

Arruda, S. de M., \& Lima, J. P. C. de; Passos, M. M. (2011). Um novo instrumento para a análise da ação do professor em sala de aula. Revista Brasileira de Pesquisa em Educação em Ciências, 11(2), 139-160.

Arruda, S. de M., \& Passos, M. M. (2015). A relação com o saber na sala de aula. Anais do $9^{o}$ Colóquio Internacional "Educação e Contemporaneidade” (pp.1-14). Aracaju: Grupo de 
Pesquisa CNPq/UFS Educação e Contemporaneidade. Retirado em 21 de abril, 2017, de: http://educonse.com.br/ixcoloquio/arruda_passos2.pdf.

Bampi, L. R., \& Moellwald, F. E.; Camargo, G. D.; Kettermann, F. M. (2013). Em meio ao PIBID e aos estágios de docência - da escrita na leitura. Zetetiké, 21(40), 105-125.

Bardin, L. (2016). Análise de conteúdo. São Paulo: Edições 70.

Bovo, A. A., Barbosa, L. A. L., Doná, E. G., \& Moreira, L. A. (2012). Descomplicando o teorema de Pitágoras. Educação Matemática em Revista, 17(36), 22-30.

Coordenação de Aperfeiçoamento de Pessoal de Nível Superior (CAPES). (2013). Diretoria de Formação de Professores da Educação Básica - DEB. Relatório de Gestão 2009/2013. Brasília: MEC/CAPES. Retirado em 16 de abril, 2014, de: https://www.capes.gov.br/images/stories/download/bolsas/2562014-relatrorio-DEB2013-web.pdf.

Carvalho, A. M. P. (2012). Os estágios nos cursos de licenciatura. São Paulo: Cengage Learning.

Carvalho, D. F. (2016). O PIBID e as relações com o saber, aprendizagem da docência e pesquisa: caracterização de uma intervenção na formação inicial de professores de matemática. Tese de Doutorado em Ensino de Ciências e Educação Matemática. Londrina: Universidade Estadual de Londrina.

Charlot, B. (2000). Da relação com o saber: elementos para uma teoria. Porto Alegre: Artmed.

Chevallard, Y. (2005). La transposición didática: del saber sábio al saber enseñado. Buenos Aires: Aique Grupo Editor.

Figueroa, T. P., Fávero, E. M. B., Almeida, L. C. A., \& Santos, J. R. (2011). Tecnologias concretas e digitais aplicadas ao processo de ensino aprendizagem de matemática inclusiva. Educação Matemática em Revista, 16(32), 52-60.

Gauthier, C., \& Martineau, S.; Desbiens, J. F.; Malo, A.; Simard, D. (2013). Por uma teoria da pedagogia: pesquisas contemporâneas sobre o saber docente. Ijuí: Unijuí.

Largo, V. (2013). O PIBID e as relações de saber na formação inicial de professores de matemática. Tese de doutorado em ensino de Ciências e Educação Matemática. Londrina: Universidade Estadual de Londrina.

Maistro, V. I. A. (2012). Formação inicial: o estágio supervisionado segundo a visão de acadêmicos do curso de Ciências Biológicas. Tese de Doutorado em Ensino de Ciências e Educação Matemática. Londrina. Universidade Estadual de Londrina.

Marchetto, R. (2016). Utilização do software MATLAB como recurso tecnológico de aprendizagem na transformação de matrizes em imagens. Revista Eletrônica de Educação Matemática, 11(1), 118-130.

Moraes, R., \& Galiazzi, M. do C. (2011). Análise textual discursiva. Ijuí: Unijuí.

Pimenta, S. G., \&Lima, M. S. L. (2011). Estágio e docência. São Paulo: Cortez Editora.

Pranke, A., \& Frison, L. M. B. (2015). Potencialização da aprendizagem autorregulada de bolsistas do PIBID/UFPel do curso de Licenciatura em Matemática através de oficinas pedagógicas. Bolema, 29(51), 223-240. 
Rodrigues, M. U., Miskulin, R. G. S., Silva, L. D., \& Ferreira, N. C. (2016). PIBID como "Terceiro Espaço" na formação de professores de matemática no Brasil. Perspectivas da Educação Matemática, 9(19), 162-183.

Tardif, M. (2002). Saberes docentes e formação profissional. Petrópolis: Vozes.

Xavier, A. C. M. Z., \& Silva, H. (2015). Produção e análise de narrativas escritas ou orais: possibilidades na investigação sobre formação de professores de matemática. Perspectivas da Educação Matemática, 8(18), 709-726. 